\title{
A produção da vida material e imaterial em comunidades chiquitanas e quilombolas em Mato Grosso: uma nova/velha forma de existência
}

\author{
Camila Emanuella Pereira Neves \\ Universidade Federal de Mato Grosso (UFMT). Cuiabá. Mato Grosso. Brasil. \\ Email: camilaemanuella@hotmail.com \\ Edson Caetano \\ Universidade Federal de Mato Grosso (UFMT). Cuiabá. Mato Grosso, Brasil. \\ Email: caetanoedson@hotmail.com

\section{Marília de Almeida Silva} \\ Universidade Federal de Mato Grosso (UFMT). Cuiabá. Mato Grosso. Brasil. \\ E-mail: lia_cultura@hotmail.com
}

Resumo: Este artigo versa sobre a formação de uma cultura diferenciada da racionalidade do modo produção capitalista, caracterizada pela incorporação de traços de resistência, solidariedade e equidadeentre seus pares. Tais características advêm da produção material e imaterial que homens e mulheres construíram historicamente e que expressam a luta pelo direito de existir em seus territórios tradicionais. O estudo envolveu duas comunidades tradicionais: indígena (Chiquitano) e quilombola (Capão Verde); as análises também privilegiaram os estudos produzidos pelo Grupo de Estudos e Pesquisa sobre Trabalho e Educação (GEPTE) nas comunidades tradicionais do Mato Grosso - Brasil. Para tanto, fundamentamo-nos no materialismo histórico dialético a partir de autores como Marx, Thompson e Mariátegui.

Palavras-chave: cultura do trabalho, comunidades tradicionais, trabalho associado, produção da vida.

\section{The production of material and immaterial lifein chiquitanas and maroons communities in Mato Grosso: a new / old form of existence}

\begin{abstract}
This article deals with the formation of a different culture than that of of capitalist productionrationality, characterized by the incorporation of features of resistance, solidarity and fairness among its peers. Such characteristics arise from material and immaterial production that men and women have built historically and express their struggle for the right to exist in their lands. The study
\end{abstract}


involved two traditional communities: indigenous (Chiquitano) and Maroons (Capon Green); the analysis also focussed on the studies produced by the Group of Studies and Research on Work and Education (GEPTE) in traditional communities of Mato Grosso - Brazil. For both, we based ourselves on historical dialecticalmaterialism based on authors such as Marx, Thompson and Mariátegui.

Keywords: work culture, traditional communities, associativework, production of life.

\section{La producción de la vida material e inmaterial en las comunidades chiquitanas y quilombolas en Mato Grosso: una nueva/antiguaforma de existencia}

Resumen: Este artículo se ocupa de la formación de una cultura distinta de la racionalidad del modo de producción capitalista, que se caracteriza por la incorporación de rasgos de resistencia, solidaridad y equidad entre sus pares. Estas características provienen de la producción material e inmaterial que hombres y mujeres construyeronhistóricamente, y que expresan la lucha por el derecho a existir en sus territorios. En el estudio participaron dos comunidades tradicionales: indígenas (Chiquitanos) y quilombola (Capon Verde); el análisis también pusoénfasis en los estudios elaborados por el Grupo de Estudios e Investigaciones sobre Trabajo y Educación (GEPTE) en las comunidades tradicionales de Mato Grosso - Brasil. Para ello, nos basamos en el materialismo histórico dialéctico a partir de autores como Marx, Thompson y Mariátegui.

Palabras clave: cultura de trabajo, comunidades tradicionales, trabajo asociado, producción de la vida.

$$
* * *
$$

\section{Introdução $^{1}$}

As comunidades e povos tradicionais compõem à classe trabalhadora e distinguem-se das demais comunidades pela história e organização social: suas vidas são forjadas na luta e na resistência pelo território, condição básica para a produção da vida. Mesmo em coexistência aos sistemas hegemônicos, antagônicos, estas comunidades/povos tradicionais tem o território como um ambiente simbólico, místico, político, econômico (Souza; Brandão, 2012), significando o lugar para além de suas fronteiras geopolíticas; significados que norteiam a vida comum das pessoas que ali vivem e reconstroem valores pelas suas experiências de produzir a vida associadamente.

Nosso trabalho versa sobre uma formação social que compreende os espaços/tempos das culturas milenares através dos saberes que são produziḑos na práxis das comunidades e povos tradicionais, cujos processos foram apreendidos, analisados e refletidos pelo Grupo de Estudos e Pesquisas sobre Trabalho e Educação (GEPTE):

que tem privilegiado análises sobre a produção associada com a finalidade de dar visibilidade a essas formas de organização, 
demonstrando assim que o modo de produção capitalista não é onipresente em nossa sociedade e que cotidianamente existem trabalhadores e trabalhadoras que lutam para produzir as suas vidas para se constituírem enquanto produtores livremente associados (Santos, 2013:169).

Olhando os povos chiquitanos e quilombolas a partir do materialismo histórico, pretendemos apreender a história, a cultura, as resistências, as contradições e o modo singular de produzir a existência. Porém, a realidade concreta não é revelada de imediato, precisamos decompor "o todo para poder reproduzir espiritualmente a estrutura da coisa, e, portanto, compreender a coisa" (Kosik, 1976:18). Nesse plano real de relações, fenômenos, fatos e contradições, o método é necessário na investigação e na análise da pesquisa empírica, pois desmistificaremos representações imediatas a respeito desses povos e relevaremos a sua essência. Para tanto, buscamos aporte em Marx e em autores marxistas como Thompson (1998) e Mariátegui (2007).

Precisamos destacar, também, que nos fundamentamos na literatura existente sobre povos e comunidades tradicionais, principalmente, construída por Grzebieluka (2012), Brandão (2012), Diegues (2000) e Cruz (2012), além das pesquisas realizadas pelo GEPTE em outras comunidades tradicionais, ao qual fazemos parte enquanto pesquisadoras.

\section{Comunidades/povos tradicionais de Mato Grosso}

No Estado de Mato Grosso, localizado no centro geodésico da América do Sul, diversas comunidades/povos tradicionais lutam e resistem pelo reconhecimento de suas identidades e territórios. Estas possuem um modo de viver e conceber o mundo peculiar e que expressa uma resistência as subjugações da lógica capitalista. Além disso, precisam constantemente lutar para que o desenvolvimento do agronegócio não avance sobre seus territórios, impossibilitando-os de existir na perspectiva que compreende a sua racionalidade, ou seja, de maneira emancipada. Assim, as comunidades/ povos tradicionais são aquelas sociedades que conservam características que remontam às sociedades antigas, como: uma interdependência da natureza, o desejo do viver comum, as redes de solidariedade, a partilha igualitária dos valores de uso, a não exploração do outro ser e a propriedade de terras comunitária.

A tradicionalidade das comunidades e povos que assim se identificam relaciona-se a identidade social dinâmica, constantemente ressignificada na realidade repleta de contradições, como resultado da própria essência humana. O tradicional é o conhecimento vivo de produzir a vida que é conduzido no espaço/ tempo pelos saberes e modificado nas experiências comuns mais emblemáticas. Assim, o conceito abarca essas comunidades, mas sim as comunidades e povos que através de suas culturas expressam identidades que representam uma dada forma de produção da vida humana. 
Todas elas apresentam relações sociais que

[...] dão características de vínculos e afeição com o lugar de existência. Os viventes deste lugar constroem laços interativos de afetividade, considerando o território como uso, apropriação, afeições e símbolos característicos de um espaço heterogêneo (Souza; Brandão, 2012:111).

Todavia o termo tradicional carrega, por vezes, uma significação negativa pela vulgarização que sofrera no mundo moderno como algo ultrapassado e que se opõe ao novo e ao progresso. As tradições carregam em si uma perspectiva de vida, de mundo e de humanidade que ultrapassa às questões materiais da produção da vida, significando e sendo (re)significada, dialeticamente, na direção de reafirmarem identidades e concepções próprias de si e das relações estabelecidas com “o outro” e a produção material e imaterial da vida. Logo,

[...] o trabalho fronteiriço da cultura exige um encontro com "o novo" que não seja parte do continuum de passado e presente. Ele cria uma ideia do novo como ato insurgente de tradução cultural. Essa arte não apenas retoma o passado como causa social ou precedente estético ela renova o passado, refigurando-o como um "entre-lugar" contingente, que inova e interrompe a atuação do presente. $\mathrm{O}$ "passado-presente" torna-se parte da necessidade, e não da nostalgia, de viver (Bhabha, 1998:27).

Desta forma, as comunidades e os povos tradicionais circunscrevem entre si alguns predicados, como acrescenta Diegues (2000:87-88):

Dependência da relação de simbiose entre a natureza, os ciclos e os recursos naturais renováveis com os quais se constrói um modo de vida; Conhecimento aprofundado da natureza e de seus ciclos, que se reflete na elaboração de estratégias de uso e de manejo dos recursos naturais. Esse conhecimento é transferido de geração em geração por via oral; Noção de território ou espaço onde o grupo social se reproduz econômica e socialmente; Moradia e ocupação do território por várias gerações, ainda que alguns membros individuais possam ter-se deslocado para os centros urbanos e voltado para a terra de seus antepassados; Importância das atividades de subsistência, ainda que a produção de mercadorias possa estar mais ou menos desenvolvida, o que implica uma relação com o mercado; Reduzida acumulação de capital; Importância dada à unidade familiar, doméstica ou comunal e às relações de parentesco ou compadrio para o exercício das atividades econômicas, sociais e culturais; Importância das simbologias, mitos e rituais associados à caça, pesca e atividades extrativistas; A tecnologia utilizada, que é relativamente simples, de impacto limitado sobre o meio ambiente. Há uma reduzida divisão técnica e social do trabalho, sobressaindo o artesanal, cujo produtor (e sua família) domina todo o processo de trabalho até o produto 
final; Fraco poder político, que em geral reside com os grupos de poder dos centros urbanos; e auto-identificação ou identificação pelos outros de se pertencer a uma cultura distinta das outras.

Para além de características comuns, essas noções compõem outras racionalidades que se opõem as formas predatórias e desumanizadoras de interversão sobre à realidade de homens e mulheres. Podemos dizer que a relação de primeira ordem entre ser humano e natureza, que traz a sua ontologia no trabalho para a satisfação das necessidades, é essencial para esses povos e regula não só a produção material como imaterial da vida. Para eles, o trabalho não é estranhado já que não existe a dominação, a subordinação e nem a exploração das potencialidades humanas. O trabalho livre e associado faz parte da vida e permite a organização da comunidade e a construção de costumes, valores, normas e simbologias, que são perpetuadas através das gerações.

Por volta dos anos 1990, a preocupação com questões ambientais (preservação da biodiversidade e o desenvolvimento sustentável) trouxe à tona as comunidades e povos tradicionais, os quais saíram da invisibilidade e foram "apropriados por um conjunto mais amplo de grupos sociais, movimentos sociais, organizações não governamentais (ONGs), pela mídia, pela academia e pelo próprio Estado, que institucionalizou essas categorias na forma de legislação, direitos e políticas públicas” (Cruz, 2012: 597).

No Mato Grosso, Sato e Silva em $2012^{2}$, iniciaram um trabalho que objetivara a auto-identificação desses povos tradicionais, no qual noventa e nove identidades foram reconhecidas, dentre elas, indígenas e quilombolas, havendo muitas outras que ainda não foram alcançadas, mas que, contudo, sabemos que na imensidão do Estado permanecem produzindo suas histórias. Assim, "o foco do mapeamento são grupos sociais que lutam contra as injustiças ambientais ocorridas em seus territórios, identidades de resistências que lutam para sair da invisibilidade e serem considerados nas políticas públicas deste Estado” (Sato; Silva, 2012:12).

As intencionalidades de trabalhos como de Sato e Silva vem de encontro com a expressiva e intensa exploração da natureza, incluindo os seres humanos, que tem levado a dizimação de variadas formas de vida pela constante ameaça aos sistemas ecológicos, seja através do desmatamento, da intervenção no leito dos rios, da instalação de micro e macro-usinas, pela monocultura, pela mineração, pelo uso de agrotóxicos, pela extinção da biodiversidade, enfim, pelo processo de maximização do lucro frente às máximas explorações de riquezas naturais e humanas.

O avanço do agronegócio nas últimas décadas tem intensificado os conflitos entre latifundiários e as comunidades e povos tradicionais, uma vez que estes, antagônicos ao sistema explorador e tirano, resistem e persistem seus costumes, tradições, modos de ver o mundo e viver. São conflitos etnoambientais, conflitos socioeconômicos, conflitos cosmopolíticos. 
As diferenças sociais não são simplesmente dadas a experiência através de uma tradição cultural já autenticada; elas são os signos da emergência da comunidade concebida como projeto - ao mesmo tempo uma visão e uma construção - que leva alguém para "além" de si para poder retornar, com um espirito de revisão e reconstrução, as condições políticas do presente (Bhabha, 1998: 21-22).

Conseguinte, o que ascende para tais conflitos são principalmente as questões ligadas à terra. As comunidades e povos tradicionais, que incorporam parte da camada popular, distinguem-se dos demais grupos pela histórica organização social, cujas vidas foram e continuam a ser forjadas na luta e na resistência pelo território, condição básica para a produção da vida, e que, ao mesmo tempo, constitui aquilo que para a classe burguesa concebe o princípio de toda acumulação, a “propriedade privada”, isto é, capital e poder. Este antagonismo define um espaço/tempo de conflito latino-americano que perdura desde o início da colonização, uma fronteira dividida por pensamentos e projetos societários divergentes, caracterizandose como um conflito econômico-político-cultural que institui diferentes concepções das organizações sociais a partir do prisma de interesses que se está atrelado, como exemplifica Mariátegui (2007:64) sobre a questão das comunidades latino-americanas, a qual

durante el período republicano, los escritores y legisladores nacionales han mostrado una tendencia más o menos uniforme a condenar la "comunidad" como un rezago de una sociedad primitiva o como una supervivencia de la organización colonial. Esta actitud ha respondido en unos casos al interés del gamonalismo terrateniente y en otros al pensamiento individualista y liberal que dominaba automáticamente una cultura demasiado verbalista y extática.

Exemplo este que dimensiona uma fronteira de racionalidades antagônicas, que se apresenta na concreticidade da vida em formas de luta de classes, pois os significados que norteiam a vida comum das pessoas que vivem e reconstroem seus valores através de suas experiências de produzir a vida associadamente e em constante resistência ao agronegócio, constroem uma nova história a partir de outra cultura do trabalho, e assim, novas/antigas formas de produzir a vida e os saberes através dessa experiência.

\section{A produção associada da vida e uma nova/antiga cultura do trabalho}

A produção associada enquanto categoria histórica nos remete às relações sociais, econômicas e culturais que os seres humanos construíram ao longo da história e que lhes confere singularidades na produção e reprodução da vida social. Tais relações estiveram presentes nas sociedades primitivas, socialista e capitalista e são mediadas pelo trabalho. Ela confere a unidade básica da sociedade dos produtores livres associados, 
instituída a partir da posse coletiva dos meios de produção, conduzindo a um conjunto de práticas que dão identidade aos diferentes grupos que assim se organizam.

De acordo com Marx (1982), o trabalho é uma condição humana consciente e proposital em que o indivíduo apropria-se da natureza, alterando seu estado natural, em seu próprio proveito. Contudo, não modifica apenas o material sobre o qual opera; transforma-se a si mesmo e forja relações entre seus pares, que se materializam de várias maneiras em diferentes modos de produção. Na produção associada, os trabalhadores e trabalhadoras se associam e produzem bens materiais e imateriais, conferindo-lhes outras representações sobre o mundo e sobre o ser humano. Portanto,

se os processos de produção da vida social se configuram como processos de produção de saberes, haveremos de ter em conta as experiências associativas que vão se tecendo em meio às contradições entre capital e trabalho. É possível afirmar que, nessas experiências, a cultura do trabalho caracteriza-se pela unidade da diversidade de culturas e experiências vividas coletivamente por trabalhadores e trabalhadoras no percurso do seu fazer-se como classe trabalhadora [...] (Tiriba; Fischer, 2012: 618).

A (re)criação de relações sociais, culturais e econômicas é o que sustenta o ideário da produção associada da vida, não se reduzindo a apropriação dos meios de produção e do processo de trabalho. Isso só é possível se pensarmos a produção associada fundada no princípio educativo do trabalho, ou seja, que o ser humano se transforma através do trabalho, cunha saberes sobre este, sobre si mesmo e sobre os outros, transmitindo o fazer e o saber a outras gerações, pois, como afirma Lukács (2009: 33) “a continuidade - transmitida pela sociedade concreta - do gênero humano (...), torna-se assim o caminho para a realização humana (genérica e, ao mesmo tempo, social e individual)”.

Coletivamente, tais trabalhadores organizam o trabalho e a vida mediante decisões democráticas, coletivas e práticas autogestionárias. Nesta, eles tomam para si o controle dos meios de produção e do processo de trabalho, o poder de decisão e o destino dos frutos do trabalho. Visualizamos, aqui, a produção associada da vida em duas comunidades/povos tradicionais matogrossenses: o quilombo Capão Verde e a etnia Chiquitano. A iniciativa ressalta o esforço de apreendermos os processos peculiares destas comunidades que, embora possuam algumas características comuns e outras que se diferem, não descrevendo um tipo ideal, apresentam diferentes identidades dependendo de como conduzem a existência e as formas do contato com o "outro" 3 .

\section{O quilombo Capão Verde}

Os quilombolas de Mato Grosso, de acordo com o Mapa Social (2002), residem em sua maioria na região dos municípios de Poconé, Nossa Senhora 
do Livramento e Vila Bela da Santíssima Trindade. Capão Verde fica localizada no município de Poconé, a 116 quilômetros da capital Cuiabá, no coração do Pantanal, numa imensidão de terras que se perde no horizonte de quem chega ao local. Lá residem 14 famílias, sendo 60 pessoas no total, que aconchegam suas casas próximas umas das outras para facilitar as relações sociais, a resolução de problemas e compartilhar o dia a dia. Sempre se sabe se alguma pessoa está doente, se alguém foi na cidade (Cuiabá), se outro está na roça, se as crianças já chegaram da escola. Como inexiste cercas ou divisórias, as pessoas e alguns animais transitam com liberdade e a roça pode ser construída onde e do tamanho que a necessidade da família exigir, sem que isso cause conflitos. Catarino explica que "se eu tenho condição de fazer um hectare, eu faço e quem tem mais, então faz duas né”.

Resistentes a colonização do branco, que os tratou com crueldade, desprezando sua cultura e sua humanidade, os escravos escapavam das senzalas e se refugiavam nas matas, construindo coletivamente locais protegidos chamados quilombos. Por isso, a manutenção dos costumes e a luta pelos seus direitos é tão forte para esses povos.

Primeiro foi transformado em assentamento, houve um projeto varredura, aí essas comunidades que eles falavam que tava com inadimplência, que tava sem pagar, transformou em assentamento a fim de poder tá recebendo recurso do governo federal, que foi na época que saiu essas construções das casas, daí depois veio o reconhecimento como quilombola (Andréia).

Guardam e veneram alguns costumes milenares, oriundos dos saberes compartilhados pelos fundadores da Comunidade como as festas de santo, a cura de doenças com ervas medicinais, a benzedura, o Muxirum ${ }^{4}$ e a Casa de Amparo ${ }^{5}$. De acordo com Thompson (1998: 22),

[...] os costumes estão claramente associados e arraigados às realidades materiais e sociais da vida e do trabalho, embora não derivem simplesmente dessas realidades. Eles podem preservar a necessidade da ação coletiva, do ajuste coletivo de interesses, da expressão coletiva de sentimentos, emoções dentro do terreno e domínio dos que deles co-participam, servindo com uma fronteira para excluir forasteiros.

Com uma cultura do trabalho que brota da produção associada da vida, destacamos que privilegiam as decisões coletivas e democráticas, a igualdade, a transmissão geracional de saberes sobre o trabalho e sobre a vida, a ajuda mútua, a ideologia de permanência na Comunidade e a resistência ao trabalho assalariado.

Tal cultura do trabalho diz respeito aos “códigos, padrões, normas, conhecimentos, saberes, crenças, valores e criações materiais (instrumentos, métodos, técnicas), (...) que regulam as ações e comportamentos huma- 
nos” (TIRIBA, 2008:48). Desse modo, os que não subsistem somente dos produtos da roça, criaram uma associação chamada Agriverde (Associação dos Agricultores e Agricultoras Afrodescendentes da Comunidade Tradicional Capão Verde) para produzir, consumir e comercializar derivados de banana da terra, fruto nativo e abundante na região. Antes da constituição da Associação, já haviam comercializado doces em calda, frutas e verduras in natura, como nos conta Maria Albertina: "desde meu pai, todo mundo aqui só mexe com a lavoura. Dava prá cada um viver da sua rocinha, sobrava pra come e prá vende”. Contudo, com ajuda voluntária de Felinto6 eles investiram os esforços e sonhos na produção de banana chips, bala de banana e farinha de banana.

Nós queríamos provar que os quilombolas analfabetos, excluídos, tem condição de fazer produtos de alta qualidade. Nosso cerrado é riquíssimo e nós queremos provar isso. Não precisa desmatar, tocar fogo, vamos trabalhar os frutos do cerrado, vamos replantar com as crianças, fazer mudinhas e ter criação solta de galinha caipira (Felinto).

Os frutos da venda dos produtos são divididos conforme a atuação na unidade de produção e os benefícios obtidos através de parcerias com ONG's, com o SEBRAE ${ }^{7}$ e do governo são estendidos também a Comunidade. Como exemplo, destacamos as casas de alvenaria, telefone, luz, água encanada, poços artesanais, cursos, entre outros.

A entrada de pessoas estranhas a Comunidade, mesmo que temporariamente para ajudar, incitou a descrença e a não participação direta na Associação por alguns moradores.

Tem alguns que não acreditam muito, ficam assim meio desconfiados: ah, vou olhar primeiro, vou pensar. Poderia dizer que Andréia, Loro e Catarino que deram a cara a tapa (Antônio).

Entretanto, todos reconhecem que a obstinação de alguns membros trouxe uma melhora na qualidade de vida da Comunidade. Mesmo assim, só se envolve na Associação quem tem habilidade e gosto pela produção dos derivados de banana.

Apesar de estarem em contato com a cultura capitalista que prega o individualismo, a competição, o lucro e a exploração, os adultos permanecem firmes com os saberes que estabeleceram na contramão dessa lógica. É claro que a idade chega e que alguns produtos não podem ser confeccionados, tendo que comprá-los no mercado, mas eles têm consciência da capacidade usurpadora do capitalismo. Também sabem que o contato com a escola e com pessoas externas à Comunidade faz com que seus saberes sejam confrontados e que muitos jovens sejam seduzidos a compor as cabines de emprego. Mas a geração amadurecida pelo tempo anseia que esses jovens não se tornem reféns do capital. Eles querem resguardar a liberdade que o capital se apodera sem o menor pudor. 


\section{A etnia Chiquitano}

O povo Chiquitano que vive no Mato Grosso ${ }^{8}$ ocupa toda a extensão da fronteira sudoeste do Estado com a Bolívia, predominantemente nos municípios de Cáceres, Porto Esperidião e Vila Bela da Santíssima Trindade, uma região de peculiaridades ambientais que compreende a partes dos biomas do Pantanal, Cerrado e Floresta Amazônica e que abriga osterritórios tradicionais identificados pelos indígenas como Lago Grande, Portal do Encantado e Barbecho.Estes territórios constituem um espaço/tempo indígena de produzir a vida material e imaterial chiquitana desde o período de colonização, em meados do século XVI, e que sofreu modificações em sua geografia pelas constantes peregrinações realizadas pelos Chiquitanos nas históricas reduções jesuítas, guerras de independência dos Estados da Bolívia e, posteriormente, na definição da fronteira entre as duas nações, e mais recentemente, nas criações de grandes propriedades latifundiárias e o avanço do agronegócio como principal exploração econômica da grande área central da América do Sul.

Essas passagens históricas provocaram grandes impactos na forma tradicional de produzir a vida do povo Chiquitano, principalmente pelo forte embate entre a cosmologia indígena chiquitana e a monocultura dos colonizadores latifundiários que hoje estão organizados no sistema capitalista de produção. Partindo da produção da vida chiquitana, deparamo-nos com uma organização social fundada na essência cosmológica ameríndia que determina e é determinada, dialeticamente, nas relações econômicas, políticas e culturais internas e externas às comunidades e que caracterizam diferentes relações de trabalho e, consequentemente, de concepção de si e do outro, ou seja, de identidade e de consciência. Logo, as relações de trabalho absorvem outra determinante questão: a questão indígena, que tem suas raízes no sistema de propriedade comum das terras (Mariátegui, 2007), fato que cumpre um grave processo de dizimação dos povos originários e suas formas de organização social por serem consideradas um entrave para o avanço capitalista na América Latina, intensamente observado no caso chiquitano pelos ataques investidos do agronegócio.

É impossível traçarmos um debate ou qualquer análise sobre qualquer aspecto da vida indígena dissociada da questão da terra. Não apenas ela corresponde a um complexo sistema simbólico na existência dos povos indígenas, como representa para a sociedade capitalista, em outros termos, também uma essência da existência do poder e do capital. Esta contradição carrega consigo o núcleo da luta Chiquitana. Para além da economia ligada aos sistemas de produção material, a economia chiquitana está entranhada aos sistemas simbólicos e imaginários da produção da vida, que possibilitam formas diferenciadas de conceber o humano, a natureza e a relação entre ambos. Como afirma Pacini (2007:19), “a economia chiquitana está baseada atualmente na agricultura e na pecuária, em aprendizado sistemático para o trabalho nas fazendas”, porém a sistematização dos trabalhos nas aldeias chiquitanas destacam elementos inerentes a história, identidade e 
cosmologia dos Chiquitanos que ultrapassam a supressão das necessidades materiais para a sobrevivência, caracterizando uma cultura do trabalho peculiar.

As relações com o trabalho ocorrem de formas distintas na organização chiquitana brasileira, sendo diferenciada de acordo com as condições relativas ao território, pois, entendemos pelas observações e relatos coletados nas aldeias Chiquitanas, que há pelo menos três formas de organização do trabalho relacionadas: 1) o trabalho associado no território coletivo; 2) o trabalho conciliado, parte associado no território coletivo, parte remunerado em fazendas vizinhas; e 3) o trabalho remunerado em fazendas vizinhas.

No território tradicional, os Chiquitanos exercem algumas práticas de subsistência, entre elas o plantio (cultivo) e a criação de animais, e mais a caça e a pesca, as quais são feitas respeitando o sistema de sazonamento das atividades. O local de plantio é chamado pelos Chiquitanos de roça, no caso da plantação comunitária, e roça-de-quintal, quando feita no quintal de suas casas para uso da família. Nelas são cultivadas, principalmente, milho, mandioca, feijão, legumes, hortaliças, arroz, cana-de-açúcar e banana, além, também, de encontramos facilmente pomares de limão, laranja e acerola. Também cultivam muitas flores e cuidam das árvores nativas. Além das roças, os Chiquitanos também criam animais, os quais vivem, na maioria das vezes, junto a eles, nos quintais.

Já os casos em que predomina o trabalho conciliado, ou seja, aquele realizado parte no território coletivo, parte remunerado em fazendas vizinhas, ocorrem devido à insuficiência de terras que garantam a subsistência, levando muitos indígenas asaírem para conseguir outras formas de trabalho remunerado, vendendo e alienando suas forças de trabalho. A respeito dessa demanda,Silva (2008:136-137) relata que:

não há como negar que o trabalho assalariado transformou-se em uma necessidade vital em decorrência da enorme perda de terras que sofreram historicamente e ao aceleramento mais recente dessas perdas, e pelo aumento crescente de necessidades de bens de consumo: bicicletas, máquinas de costura, remédios, roupas, óleo de cozinha e etc.

Tal forma de trabalho, ainda assume forma predominante nas comunidades cujo direito ao território tradicional fora negado e invisibilizado, configurando-se como trabalho organizado nas relações de exploração em fazendas vizinhas, as mesmas que invadem e anulam tal direito e outros como o direito a vida e a dignidade. Nestas fazendas, os Chiquitanos ficam encarregados dos trabalhos braçais, tais como o manejo do gado, a construção e manutenção das estruturas da fazenda, as limpezas dos pastos, os serviços domésticos,etc, cuja a maioria das trabalhadoras e trabalhadores está sujeita ao trabalho temporário, no qual não possuem os registros devidos na carteira de trabalho assegurados pela lei, nem qualquer outra garantia de direito trabalhista. 
Mantendo estes trabalhadores indígenas na clandestinidade e ilegalidade os fazendeiros vão mais longe. Ameaçam aqueles que se assumirem indígenas a perda da única fonte de sobrevivência, de persegui-los, de prejudicarem familiares ou outros parentes e, assim, são proibidos de falarem na língua materna chiquitana, de realizarem as festas e rituais tradicionais, além de procurarem seus direitos como indígenas nacionais. Tal questão incide na problemática que emerge dos conflitos mais recentes, correspondendo a um processo de negação da etnicidade indígenas dos Chiquitano, cujo advém de uma campanha política que visa agregar a imagem Chiquitano às relações diretas de ocupação imigratória, tratando, assim, estas mulheres e homens Chiquitanos como estrangeiros e descendentes de bolivianos que vêm usurpar das terras brasileiras - entre outras colocações pejorativas que já estão disseminadas no senso comum brasileiro sobre os indígenas e os imigrantes.

Diante do exposto, compreendemos as interseções entre economias distintas, sendo o capitalismo a influência externa e hegemônica que pressiona a outra forma econômica e cultural da vida chiquitana, pela impossibilidade que a comunidade indígena tem de sobreviver sem sua terra demarcada. Nessa situação de trabalho remunerado, portanto inserido diretamente ao capitalismo, os Chiquitanos se veem encurralados, uma vez que a eminente intimidação de perder o trabalho mantêm os Chiquitanos amarrados, além de degenerar o sentimento de ser humano, agride o sentido mais íntimo de ser: a identidade de si. Pensam não ter escolhas, pois para todos os lados o seu trabalho está sujeito ao preconceito e a exploração. Para estes Chiquitanos, reféns da perversidade do agronegócio, a produção da vida é permanentemente contraditória, pois:

se o produto do trabalho não pertence ao trabalhador, um poder estranho [que] está diante dele, então isso só é possível pelo fato de [o produto do trabalho] pertencer a um outro homem fora do trabalhador. Se a sua atividade lhe é martírio, então ela tem que ser fruição e alegria de viver para um outro. Não os deuses, não a natureza, apenas o homem mesmo pode ser este poder estranho sobre o homem (MARX, 2004: 86).

Todaviao que fortalece os Chiquitanos a permanecerem na luta pelo direito de ser indígena, ou seja, produzirem a vida material e imaterial atravésdo trabalho livre e associado no seu território tradicional emancipadoé a identidade cosmológica de apreensão de uma organização social fundada em princípios de solidariedade, justiça, comunhão, equidade e liberdade enquanto valores e direitos de todos os seres, humanos e não-humanos, e que se forjam pela cultura do trabalho seja pela experiência da produção associada ou pela consciente resistência despertada pelas contradições presentes no trabalho absorvido pelo modo de produção capitalista. 


\section{Considerações Finais}

Temos convicção que, no que condiz a vida dessas comunidades/ povos tradicionais, é concreta a resistência da qual se revestem para lutar pelo direito à vida que acreditam e que os identifica. Silva e Sàto (2012:19), enfaticamente, apontam que:

é fato que as comunidades foram relegadas e/ou colocadas à margem da história oficial, mas também é fato que resistiram e resistem ao pulsar no cultural de suas realidades. O modo de vida destes grupos vem demonstrando uma intrínseca relação com a natureza e, em muitos casos, a presença destes povos tem sido um importante aliado na preservação dos ecossistemas. Assim, vemos nas últimas décadas, a emergência destes protagonistas portadores de identidades coletivas e étnicas, que buscam num cenário de lutas, em especial por conflitos agrários e ambientais, reivindicar seus direitos coletivos por ambientes preservados.

Importa tornarmos visíveis os sujeitos históricos, suas experiências e seus saberes inerentes aos espaços/tempos das culturas milenares das comunidades e povos tradicionais, que, para além de terem características comuns, apresentam especificidades que podem mudar o rumo, não só da teoria, mas de toda a história humana, pois há nestes a insurgência do novo, a partir do passado-presente, uma possibilidade concreta de emancipação. Com foco na produção associada e na produção de saberes que originam desta, os trabalhos do GEPTE apontam para a prevalência deste modo de organização da vida social como "alternativa histórica de organização do trabalho” (Santos, 2013: 169), “uma possibilidade de organizar o processo do trabalho, com princípios que se diferenciam da lógica capitalista, cujo trabalho manual e intelectual caminham juntos e sem fragmentação” (Neves, 2013: 197), onde “as pessoas se reconhecem primeiro como seres humanos [...], se baseiam na ajuda mútua [...], se solidarizam na partilha [...], dentro do contexto de inquestionável respeito à natureza" (Guerino, 2013:127).

Podemos observar tais características no quilombo Capão Verde, através da experiência com a produção associada dos derivados da banana da terra, que privilegia saberes coletivos e um conhecimento da natureza que se expressa na opção pela matéria-prima. Tal produção é conduzida por uma cultura do trabalho construída e reconstruída pelas trabalhadoras e trabalhadores, sem controle do ritmo e do tempo de trabalho, já que internalizam a atividade como parte da produção da vida e com a distribuição igualitária dos frutos do trabalho. Além disso, os saberes ancestrais extrapolam o âmbito da produção material da vida e mantêm-se intensos nas tradições, materializadas nas festas de santo, na utilização de ervas e raízes para a cura de enfermidades, nas danças, na oralidade,no educar, na permanência e resistência na terra,na preservação e na manutenção da natureza. 
Já as vozes silenciadas do povo Chiquitano no Brasil nos contam partes de um processo invisibilizado de uma organização social ameríndia, que luta por existir conforme sua racionalidade cosmológica - antissistema e emancipatória - devido à ameaça eminente que os sufoca e extermina suas gerações passadas e futuras, mas que, concomitantemente, reverbera em uma consciência social de identidade étnica-cultural e das relações de poder entre o Estado, o capital (personificado no agronegócio), a sociedade não indígena e os povos indígenas. Logo, os saberes ancestrais advindos da experiência secular que designou os traços da identidade indígena Chiquitano, que são saberes legitimados e valorizados pelos Chiquitanos (sendo as anciãs e os anciãos os portadores da maior gama de conhecimento da produção material e imaterial da vida, e que por isso devem ser repassados por estes aos menores, na racionalidade indígena), formam a unidade de saberes da experiência Chiquitana de como educar suas crianças, jovens e mesmos os adultos; de como ser Chiquitano significa ser natureza, ser o outro, ser o peixe, é falar com a música, dançar a devoção; e, principalmente, de respeitar e desejar o bem-viver de todas e todos como seres essenciais.

A essência da produção da vida quilombola e chiquitana, do seu existir e resistir num mundo tão contraditório e desigual, nos revela que pertencer a uma cultura distinta, tanto no âmbito material como imaterial da vida, e divergente da cultura hegemônica não é uma tarefa branda. Requer constantemente uma tomada de consciência coletiva de classe e de identidade que, por vezes, causa conflitos entre o saber e o fazer. No entanto, esses povos tradicionais permanecem resistindo e sendo desafiados cotidianamente a se serem dirigentes da sua própria existência. 


\section{Notas}

${ }^{1}$ O estudo contou com apoio do Conselho Nacional de Desenvolvimento Científico e Tecnológico (CNPq), por meio do Edital Universal (2014 - 2017).

${ }^{2}$ Este estudo intitula-se Mapa Social: mapeando os grupos sociais do estado de Mato Grosso - Brasil.

${ }^{3}$ Brandão (2012) nos traz a concepção de situação de fronteira em que diferentes culturas se encontram e geram conflitos/contradições. Contudo, lembramos que o outro é visto como tal tanto pelo dominante como pelo dominado. A aproximação do outro cria uma situação de fronteira, de resistência, mas provoca também mudanças.

${ }^{4} \mathrm{O}$ muxirum consiste em uma prática antiga de realizar o trabalho contando com a ajuda de outras pessoas. Em outras palavras, ao invés de realizar sozinho uma atividade (carpir, roçar, colher, fiar), convida-se os vizinhos para participarem e assim, quando o vizinho precisar o muxirum é feito em sua terra. O trabalho que uma pessoa realizaria em uma semana é realizado coletivamente em um dia, diminuindo o desgaste da força de trabalho e ampliando as redes de solidariedade

${ }^{5}$ A Casa de Amparo é a casa feita de barro e madeira, mantida na Comunidade para receber parentes que evadiram da mesma, até que consigam se restabelecer.

${ }^{6}$ Felinto é um militante da Educação Popular, aposentado da Universidade Federal de Mato Grosso que presta ajuda voluntária a várias comunidades tradicionais de Poconé.

${ }^{7}$ O SEBRAE (Serviço Brasileiro de Apoio às Micro e Pequenas Empresas) é uma entidade privada que prestou assessoria na confecção de rótulos e levou cursos e capacitações para Capão Verde.

${ }^{8}$ Além do Mato Grosso, o povo Chiquitano reside, desde a sua formação étnica durante às reduções jesuítas no século XIV, nas áreas territoriais que hoje compreendem a Bolívia (Gran Chiquitania até Santa Cruz) e na fronteira com o Estado de Mato Grosso do Sul, ainda no Brasil. Todavia, pela complexidade do estudo, optou-se por contemplar as mulheres e os homens Chiquitanos que vivem no Mato Grosso nas aldeias Vila Nova Barbecho, Fazendinha, Anamastacaama e Santa Aparecida. 


\section{Bibliografia}

Bhabha, Homi (1998), O local da cultura, Editora da UFMG, Belo Horizonte.

Brandão, Carlos R. \& LealL, Alessandra (2014), “Comunidade tradicional: conviver, criar, resistir”, em Revista da ANPEGE, 9, pp. 73-91,Disponível em: http://anpege.org.br/revista/ojs-2.2.2/index.php/anpege08/article/view/ 205, [consultado em 23-01-2014.

Ídem \& Souza, Angela F. G. de (2014), “ Ser e viver enquanto comunidades tradicionais”, Mercator, Fortaleza, 26, pp. 109 - 120. Disponível em: http:/ /www.mercator.ufc.br, [consultado em 20-01-2014].

Cruz, Valter do C. (2012), “Povos e comunidades tradicionais”, Dicionário da Educação do Campo, Expressão Popular, São Paulo.

Diegues, Antonio C. S. (2000), O mito moderno da natureza intocada, Hucitec - Núcleo de Apoio à Pesquisa sobre Populações Humanas e Áreas Úmidas Brasileiras, USP, São Paulo.

Grzebieluka, Douglas (2014), "Por uma tipologia das comunidades tradicionais brasileiras”, Revista Geografar, Curitiba, 1, pp. 116-137, Disponível em: http://www.ser.ufpr.br/geografar, [consultado em 12-012014].

Guerino, Mariana F. (2013), O movimento dos saberes na produção da vida na Comunidade Quilombola Campina de Pedra, Dissertação de Mestrado em Educação, Mato Grosso: Instituto de Educação, Universidade Federal do Mato Grosso.

Kosik, Karel (1976), Dialética do concreto, Paz e Terra, Rio de Janeiro.

Lukács, Giorgÿ (2009), Arte e Sociedade, Escritos estéticos,1932-1967, Editora UFRJ, Rio de Janeiro.

Mariátegui, José C. (2007), Sete ensayos de interpretación de la realidad Peruana, Biblioteca Ayacucho, Nenezuela.

Marx, Karl (2004), Manuscritos econômico-filosóficos, Boitempo, São Paulo.

Idem (1982), O Capital, Crítica da economia política, Livro Primeiro - O processo de produção do capital, DIFEL, São Paulo.

Neves, Camila Emanuella Pereira (2013), A produção associada em Capão Verde: entre bananas saberes e utopias, Edufmt, Cuiabá.

Pacini, Aloir (2007), Identidade étnica e território Chiquitano na fronteira (Brasil-Bolívia), Tese de Doutorado em Antropologia Social, Instituto de 
Filosofia e Ciências Sociais, Universidade Federal do Rio Grande do Sul, Porto Alegre.

Santos, Lirian K. (2013), Trabalho, produção associada e produção de saberes na comunidade tradicional Imbê - MT, Dissertação de Mestrado em Educação,nInstituto de Educação, Universidade Federal do Mato Grosso, Mato Grosso.

Silva, Lígia O. (2008), Terras devolutas e latifúndio: efeitos da Lei de 1850, Editora da UNICAMP, Campinas.

Tiriba, Lia \& Fischer, Maria C. B. (2012), “Produção Associada e autogestão”. Dicionário da Educação do Campo, Expressão Popular, São Paulo.

Tiriba, Lia \& Picanço, Iracy (2004), O trabalho como princípio educativo no processo de produção de uma "outra economia”, Trabalho e Educação: arquitetos, abelhas e outros tecelões da economia popular solidária,Idéias \& Letras, São Paulo.

Thompsom, Edward P. (1998), Costumes em comum, Estudos sobre a cultura popular tradicional. São Paulo, Companhia da Letras, São Paulo.

Recibido: 09.03.2015

Aceptado: 10.04.2015 